\title{
ОЦЕНКА КОГНИТИВНОЙ ГОТОВНОСТИ ВЫПУСКНИКА ПЕДАГОГИЧЕСКОГО КОЛЛЕДЖА К ПРОЕКТНОЙ ДЕЯТЕЛЬНОСТИ
}

\author{
B.3. Юсупов \\ Московский гуманитарный университет \\ C.B. Капин \\ Норильский педагогический колледж
}

\begin{abstract}
Аннотация: В статье обосновано понимание когнитивного критерия готовности как признака, на основании которого оиенивается уровень качества знания будущзего педагога о проектной деятельности.
\end{abstract}

Ключевые слова: проектная деятельность, когнитивная готовность, критерии, показатели

\section{ASSESSMENT OF THE COGNITIVE READINESS OF A TEACHER TRAINING COLLEGE GRADUATE FOR PROJECT ACTIVITIES}

\author{
V.Z. Yusupov \\ Moscow University for the Humanities \\ S.V. Kapin \\ Norilsk pedagogical College
}

\begin{abstract}
The article substantiates the understanding of the cognitive readiness criterion as a sign on the basis of which the level of quality of the future teacher's knowledge about project activities is assessed.
\end{abstract}

Keywords: project activity, cognitive readiness, criteria, indicators

Готовность к проектной деятельности выпускника педагогического колледжа - это интегративное личностное образование в структуре его готовности к педагогической деятельности, включающее устойчивое единство составляющих её компонентов: мотивационного; когнитивного, операционного, продуктивного, личностного.

Проблема формирования перечисленных или близких к ним по функциональному назначению компонентов изучалась в исследованиях Н.А. Гордеевой, И.В. Корякиной, Г.Г. Митрофановой, Т.А. Панчук, А.А. Сараевой, В.П. Фалько, Е.А. Шейблита и др. Все они в контексте проблематики своего исследования раскрывают содержание и предлагают способы формирования и оценивания когнитивного компонента готовности к проектной деятельности. При этом термин «критерий» чаще всего используется в его наиболее распространённом значении: признак, на основании которого осуществляется оценка уровня сформированности названного компонента. Качественную и/или количественную характеристику критерия, реальное проявление, того, по чему можно судить об уровне развития выделенного признака, 
оценивается исследователями с помощью определённой совокупности показателей.

Г.Г. Митрофанова считает, что когнитивный компонент готовности к проектной деятельности оценивается на основе сформированности «системных, прочных и глубоких знаний о сущности, логике, этапах этой деятельности» (Митрофанова, 2012: 6). Организованный автором исследования констатирующий этап эксперимента показал, что $58,6 \%$ респондентов ничего не знают о проектной деятельности, а остальные студенты обладают лишь отрывочными сведениями. В эксперименте по формированию готовности студентов колледжа к проектной деятельности в процессе обучения иностранному языку автором исследования были организованы специальные учебные занятия. Их содержание включало учебный материал, раскрывающий сущность понятий «проект», «проектная деятельность», а также характеристику функций, принципов, алгоритма проектной деятельности, классификаций проектов по разным основаниям. В результате $82,8 \%$ студентов показали высокий уровень сформированности когнитивного компонента (Митрофанова, 2012: 15).

С точки зрения А.А. Сараевой когнитивный критерий готовности будущих учителей к проектной деятельности «включает в себя комплекс знаний о её сущности и дидактических особенностях; понимание важности проектной деятельности в жизни человека; владение содержанием и последовательностью проектирования, интеллектуальную мобильность» (Сараева, 2011: 11). Формирование этих знаний в экспериментальной работе обеспечивалось за счёт специально введённого спецкур$\mathrm{ca}$, результаты изучения которого показали повышение в 2 раза уровня теоретических знаний студентов о проектной деятельности.

Приведённые примеры демонстрируют традиционную почти для всех исследователей практику описания когнитивного критерия готовности студентов к проектной деятельности через перечисление элементов теоретического знания и организацию их усвоения в процессе специально организованных учебных занятий, эффективность которых подтверждается цифрами значительного повышения уровня сформированности когнитивного компонента. В качестве показателей завершённости этого процесса чаще всего выступает лишь полнота (объём) усвоенных единиц содержания обучения проектной деятельности.

Некоторые исследователи (как, например, уже упоминавшаяся Г.Г. Митрофанова) стремятся выделить качественные характеристики знаний о проектной деятельности, называя их системными, прочными, глубокими, мобильными, осознанными и т. п. Однако суть этих качеств авторами глубоко не раскрывается, а их проявления не диагностируются.

Авторы научных работ, как правило, выделяют три уровня сформированности когнитивного компонента готовности к проектной деятельности: низкий, средний и высокий или их аналоги (например, пороговый, достаточный, оптимальный). Ю.В. Веселова считает целесообразным выделение фрагментарного, конструктивного и автономного уровней (Веселова, 2007); а Т.Л. Стенина - интуитивно-репродуктивного, реконструктивного и креативного уровней (Стенина, 2011). По своим 
содержательным характеристикам названные Ю.В. Веселовой и Т.Л. Стениной уровни вполне соотносимы с традиционно выделяемыми низким, средним и высоким уровнями. Вместе с тем, преимущество обозначений авторами уровней в том, что в своих названиях они отражают логику процесса формирования компонентов готовности к проектной деятельности.

В нашей исследовательской и экспериментальной работе по формированию когнитивного критерия оценивания готовности к проектной деятельности будущего педагога внимание было сконцентрировано на выявлении и обосновании наиболее значимых для формирования этой готовности качеств знания.

В педагогической науке под качеством знания понимается система всех его существенных, относительно устойчивых свойств и характеристик, выделение и обоснование которых содержится в работах М.И. Зайкина, Т.В. Кудрявцева, И.Я. Лернера, Т.И. Огородникова, В.А. Ситарова, М.Н. Скаткина, В.А. Сластенина, С.Г. Шаповаленко и др. Чаще всего в состав этой системы включаются двенадцать качеств знания. И.Я. Лернер, объединив их попарно, выделил следующие: полнота и глубина, систематичность и системность, оперативность и гибкость, конкретность и обобщённость, свёрнутость и развёрнутость, осознанность и прочность, между которыми проявляют себя тесные интегративные связи (Лернер, 1978: 13).

Т.И. Шамова и Т.М. Давыденко предложили практически те же двенадцать качеств знаний, заменив только гибкость на действенность, что не принципиально, поскольку содержательно характеристика действенности знаний достаточно близка к описанию И.Я. Лернером гибкости знания. Т.И. Шамова и Т.М. Давыденко в сформированной системе качеств знания выделили три интегративных: системность, действенность и прочность, показав, что каждое из них является результатом интеграции определённой совокупности других качеств (Шамова, 1990: 34). При этом авторы уточнили, что системность интегрирует наибольшее количество качеств знаний.

Наряду с этим, в педагогической литературе используются и другие основания для классификации качеств знаний. Среди них наиболее значимый в контексте нашего исследования является подход, основанный на выделении двух или трёх сторон качества знаний (Ю.К. Итин, Т.Л. Коган, Э.А. Красновский и др.). В трёхсторонней структуре выделяются три группы системы качеств: содержательные (предметно-содержательные), операциональные (содержательно-деятельностные, процессуальные), личностные (содержательно-личностные). К предметно-содержательном относятся знания отдельных сторон, элементов, единичных свойств содержания предметного материала. В состав этой группы качеств чаще всего входят: полнота, глубина, системность, систематичность. В структуре содержательно-деятельностной стороны рассматриваются: прочность, осознанность, конкретность, обобщённость, обеспечивающие способность осуществлять такие действия со знанием, как актуализация, перестройка, реконструкция, применение в знакомой или сходной ситуации. Личностную сторону составляют качества знания, результирующие влияние 
процесса обучения на развитие качеств личности, прежде всего самостоятельности, инициативности, творчества.

Ряд исследователей (И.Я. Лернер, М.Н. Скаткин, В.В. Краевский, И.С. Булатова и др.) на основании уровневого подхода устанавливают взаимосвязь качеств знания и уровней их усвоения (низкий, средний, высокий). Среди качеств знания, формируемых на первом уровне, учёные чаще всего называют: полноту, глубину, систематичность, системность, т.е. качества, относящиеся к предметно-содержательной стороне знания. Соглашаясь с этой точкой зрения, мы принимаем во внимание, что среди перечисленных качеств личности роль интегративного может выполнять полнота или системность знания. В нашем исследовании в качестве интегративного рассматривается полнота знания, которую можно диагностировать уже на начальном этапе обучения студентов проектной деятельности. В отличие от полноты, о системности знаний по проектной деятельности можно судить только в период завершения обучения в колледже.

В осуществляемой экспериментальной работе под полнотой знаний (вслед за И.Я. Лернером) мы понимаем «количество программных знаний», или, говоря другими словами, количество усвоенных элементов содержания обучения проектированию. Полнота знания свидетельствует об адекватности усвоения и воспроизведения элементов знания о его сущностных свойствах, а также о нормативной последовательности действий в проектной работе. Количество «программных знаний» задаётся принципом нормативности, который характеризуется В.3. Юсуповым как «соответствие квалификационным, возрастным, дидактическим и другим нормам» (Юсупов, 2019: 35).

На втором (среднем) уровне освоения знаний в качестве приоритетных в исследованиях преимущественно называются осознанность и прочность, к которым добавляются, например, развёрнутость, свёрнутость знания, фактически характеризующих операциональную (процессуальную) сторону применения знания. Осознанность выражается в понимании связей между элементами знания, в умении их доказывать, конструировать новые варианты связей и отношений; а прочность состоит, говоря словами И.Я. Лернера, в устойчивой «фиксации в памяти системы существенных связей и способов их применения» (Лернер, 1978: 38). Среди перечисленных качеств роль интегративного мы, вслед за Т.И. Шамовой и Т.М. Давыденко, отводим прочности знания.

В состав третьего (высокого) уровня исследователи неизменно включают гибкость знания как наиболее значимого результата освоения и применения знания, который демонстрируется способностью самостоятельно находить способ применения знаний при изменении ситуации или различных способов в одной и той же ситуации.

В ряде исследований (например, Булатова, 2011: 173) обращается внимание, что формируемые на более низком уровне качества знания, закрепляются и развиваются на вышестоящем уровне. 
В нашем исследовании выделены следующие уровни сформированности когнитивного компонента:

- низкий (репродуктивный) уровень, демонстрирующий осознанно воспринятое, зафиксированное в памяти и воспроизведенное знание о проектной деятельности, отражающее полноту усвоения элементов содержания обучения проектированию, достаточный уровень которого задан образовательной программой;

- конструктивный уровень, показывающий прочность усвоенного знания, которая проявляется в умении перестраивать, видоизменять, преобразовывать имеющееся знание о проектной деятельности в новую его конструкцию; применять это знание в ситуации, рассмотренной на учебном занятии, представленной в учебной литературе или сходной с описанной в ней,

- творческий уровень, свидетельствующий о сформированной гибкости знания как способности создавать субъективно новое знание, находить новый способ применения знаний при изменении ситуации или новые варианты использования известного способа в одной и той же ситуации.

Полученные в нашей экспериментальной работе представления о содержании когнитивного критерия готовности будущего педагога к проектной деятельности представлены в табл. 1.

Таблица 1

\section{Характеристика когнитивного критерия готовности к проектной деятельности выпускника педагогического колледжа}

\begin{tabular}{|c|c|c|c|c|}
\hline \multirow{2}{*}{$\begin{array}{c}\text { Интегратив- } \\
\text { нье показатели } \\
\text { качества знания }\end{array}$} & \multirow{2}{*}{$\begin{array}{c}\text { Формьл } \\
\text { самопроверки } \\
\text { и проверки }\end{array}$} & \multicolumn{3}{|c|}{ Уровни усвоения знаний } \\
\hline & & $\begin{array}{c}\text { Низкий } \\
\text { (репродуктивныгй) }\end{array}$ & $\begin{array}{c}\text { Средний } \\
\text { (конструктивный) }\end{array}$ & $\begin{array}{c}\text { Высокий } \\
\text { (творческий) }\end{array}$ \\
\hline $\begin{array}{l}\text { Полнота усвое- } \\
\text { ния элементов } \\
\text { знания содер- } \\
\text { жания обуче- } \\
\text { ния проектной } \\
\text { деятельности }\end{array}$ & $\begin{array}{l}\text { Tест, устные во- } \\
\text { просы на вос- } \\
\text { произведение } \\
\text { элементов зна- } \\
\text { ния и после- } \\
\text { довательности } \\
\text { проектных дей- } \\
\text { ствий, а также их } \\
\text { интерпретация }\end{array}$ & $\begin{array}{l}\text { Усвоение 30\%- } \\
\text { 59\% нормативно } \\
\text { установленных } \\
\text { элементов со- } \\
\text { держания обуче- } \\
\text { ния проектной } \\
\text { деятельности. } \\
\text { Воспроизведение } \\
\text { знаний осущест- } \\
\text { вляется, преи- } \\
\text { мущественно, в } \\
\text { интерпретациях } \\
\text { рассмотренных на } \\
\text { учебных занятиях } \\
\text { и (или) представ- } \\
\text { ленных в различ- } \\
\text { ных источниках } \\
\text { информации }\end{array}$ & $\begin{array}{l}\text { Усвоение } 60 \%- \\
79 \% \text { нормативно } \\
\text { установленных } \\
\text { элементов со- } \\
\text { держания обуче- } \\
\text { ния проектной } \\
\text { деятельности. } \\
\text { Частичное вос- } \\
\text { произведение } \\
\text { элементов зна- } \\
\text { ния в интерпре- } \\
\text { тациях, отлича- } \\
\text { ющихся от ранее } \\
\text { рассмотренным } \\
\text { или приведен- } \\
\text { ных в различ- } \\
\text { ных источниках } \\
\text { информации }\end{array}$ & $\begin{array}{l}\text { Полный или при- } \\
\text { ближающийся к } \\
\text { полному ( } 80 \%- \\
100 \%) \text { объём } \\
\text { усвоенных зна- } \\
\text { ний. Воспроизве- } \\
\text { дение элементов } \\
\text { знания в различ- } \\
\text { ных интерпрета- } \\
\text { циях, демонстри- } \\
\text { рующих знание } \\
\text { дополнительных } \\
\text { источников ин- } \\
\text { формации }\end{array}$ \\
\hline
\end{tabular}


Продолжение таб. 1

\begin{tabular}{|c|c|c|c|c|}
\hline \multirow{2}{*}{$\begin{array}{c}\text { Интегратив- } \\
\text { ные показатели } \\
\text { качества знания }\end{array}$} & \multirow{2}{*}{$\begin{array}{c}\text { Формыл } \\
\text { самопроверки } \\
\text { и проверки }\end{array}$} & \multicolumn{3}{|c|}{ Уровни усвоения знаний } \\
\hline & & $\begin{array}{c}\text { Низкий } \\
\text { (репродуктивньй) }\end{array}$ & $\begin{array}{c}\text { Средний } \\
\text { (конструктивный) }\end{array}$ & $\begin{array}{c}\text { Выссокий } \\
\text { (творческий) }\end{array}$ \\
\hline $\begin{array}{l}\text { Прочность } \\
\text { усвоенного зна- } \\
\text { ния, демонстри- } \\
\text { руемого в ситу- } \\
\text { ациях учебного } \\
\text { проектирования }\end{array}$ & $\begin{array}{l}\text { Вопросы и зада- } \\
\text { ния на понима- } \\
\text { ние и преобра- } \\
\text { зование знаний } \\
\text { в создаваемой } \\
\text { педагогом ситу- } \\
\text { ации учебного } \\
\text { проектирования }\end{array}$ & $\begin{array}{l}\text { Выполнение части } \\
\text { (не менее третьей } \\
\text { части) заданий на } \\
\text { преобразования } \\
\text { знания в его новую } \\
\text { конструкцию. Пре- } \\
\text { имущественное } \\
\text { использование в } \\
\text { учебном проекти- } \\
\text { ровании образца, } \\
\text { аналога, прототи- } \\
\text { па, рассмотрен- } \\
\text { ного на учебном } \\
\text { занятии и (или) } \\
\text { представленного в } \\
\text { источниках инфор- } \\
\text { мации. Необходи- } \\
\text { мость дополни- } \\
\text { тельной помощи, } \\
\text { контроля для вы- } \\
\text { полнения требова- } \\
\text { ний педагога }\end{array}$ & $\begin{array}{l}\text { Выполнение } \\
\text { большей ча- } \\
\text { сти заданий на } \\
\text { преобразования } \\
\text { усвоенного зна- } \\
\text { ния в его новую } \\
\text { конструкцию. } \\
\text { Быстрое и пра- } \\
\text { вильное выпол- } \\
\text { нение заданий } \\
\text { на применение } \\
\text { знания в типич- } \\
\text { ной ситуации. } \\
\text { Наблюдаются } \\
\text { трудности при } \\
\text { выполнении } \\
\text { обучающимся } \\
\text { задания, но } \\
\text { после помощи } \\
\text { педагога он } \\
\text { успешно справ- } \\
\text { ляется с ним }\end{array}$ & $\begin{array}{l}\text { Полноценное } \\
\text { самостоятель- } \\
\text { ное выполне- } \\
\text { ние задания на } \\
\text { преобразования } \\
\text { усвоенного зна- } \\
\text { ния в его новую } \\
\text { конструкцию. } \\
\text { Проявление ини- } \\
\text { циативы и твор- } \\
\text { чества. Наблюда- } \\
\text { ется стремление } \\
\text { использовать } \\
\text { дополнитель- } \\
\text { ные источники } \\
\text { информации }\end{array}$ \\
\hline $\begin{array}{l}\text { Гибкость в при- } \\
\text { менения знаний } \\
\text { о проектирова- } \\
\text { нии в ситуациях } \\
\text { осуществления } \\
\text { профессиональ- } \\
\text { ной деятельно- } \\
\text { сти }\end{array}$ & $\begin{array}{l}\text { Задания, требу- } \\
\text { ющие самостоя- } \\
\text { тельно находить } \\
\text { способ приме- } \\
\text { нения знаний в } \\
\text { ситуациях про- } \\
\text { фессиональной } \\
\text { деятельности }\end{array}$ & $\begin{array}{l}\text { Применение на } \\
\text { практике знаний, } \\
\text { преимущественно } \\
\text { основанных на го- } \\
\text { товом, разработан- } \\
\text { ном продукте про- } \\
\text { ектирования, без } \\
\text { учёта особенно- } \\
\text { стей конкретной } \\
\text { ситуации профес- } \\
\text { сиональной дея- } \\
\text { тельности. Варьи- } \\
\text { рование способов } \\
\text { действия осущест- } \\
\text { вляется только с } \\
\text { помощью педагога }\end{array}$ & $\begin{array}{l}\text { Применение на } \\
\text { практике знаний, } \\
\text { преимущественно } \\
\text { основанных на } \\
\text { видоизменённом, } \\
\text { преобразованном, } \\
\text { реконструиро- } \\
\text { ванном продукте } \\
\text { проектирования с } \\
\text { учётом особенно- } \\
\text { стей конкретной } \\
\text { ситуации про- } \\
\text { фессиональной } \\
\text { деятельности. } \\
\text { Наблюдаются } \\
\text { затруднения, но с } \\
\text { помощью педа- } \\
\text { гога проявляется } \\
\text { способность } \\
\text { выбора оптималь- } \\
\text { ных для конкрет- } \\
\text { ной ситуации спо- } \\
\text { собов действий }\end{array}$ & $\begin{array}{l}\text { Целесообразно } \\
\text { варьируются спо- } \\
\text { собы действий; } \\
\text { перестраивается } \\
\text { система знаний и } \\
\text { навыков в соот- } \\
\text { ветствие с новы- } \\
\text { ми условиями; } \\
\text { осуществляется } \\
\text { быстрое переклю- } \\
\text { чение с одного } \\
\text { известного спо- } \\
\text { соба действия на } \\
\text { другой в ситуаци- } \\
\text { ях осуществления } \\
\text { профессиональ- } \\
\text { ной деятельности }\end{array}$ \\
\hline
\end{tabular}


Количественная оценка качества знаний многими исследователями осуществляется с использованием дифференциальных и комплексных методов квалиметрии - науки об изменениях и оценке качества объектов, процессов, явлений. К их числу с полным основанием можно отнести качество знаний. Такая оценка осуществляется по параметрическим показателям, основанным на оценке параметров, к которым относятся среднее арифметическое, среднеквадратическое отклонение, дисперсия.

Интерпретацией дифференциального метода квалиметрии являются методы поэлементного и пооперационального анализа, применяемый А.В. Усовой, А.А. Кыверялгом, Л.Д. Стариковой и другими учёными для измерения полноты усвоенных студентами знаний. Методы основаны на установлении количества подлежащих усвоению обучающимися структурных единиц знания, которые одни исследователи называют элементами, другие - единичными свойствами (в квалиметрии единичное свойство - это показатель качества, относящийся к одной характеристике).

В оценке когнитивного компонента готовности студентов к проектной деятельности целесообразно применять методы поэлементного и пооперационного анализа, которые использовала А.В. Усова с её терминологий и обозначениями коэффициентов (Усова, 1986). Возможности этих методов можно расширить за счёт вычисления не только индивидуального, но и группового коэффициента полноты усвоения элементов знания содержания обучения проектированию. При этом полученные коэффициенты дадут достаточно объективное и убедительное основание для определения уровня и выставления студенту оценки за полноту усвоенных знаний.

Таким образом, рассматриваемый в статье когнитивный критерий - это признак, на основании которого возможно в количественных показателях оценить уровень полноты, глубины и гибкости как интегративных свойствах качества знания будущего педагога о проектной деятельности.

\section{СПИСОК ЛИТЕРАТУРЫ}

Булатова, И.С. (2011) Качество знаний как сохраняемые модели содержания образования при обучении в вузе //Теория и практика общественного развития. № 3. С. 171-174.

Веселова, Ю.В. (2007) Становление проектной культуры студентов в образовательном пространстве педагогического колледжа: Автореф. дис. ... канд. пед. наук. Омск, 22 с.

Лернер, И.Я. (1978) Качества знаний учащихся. Какими они должны быть? М.: Знание. $48 \mathrm{c.}$

Митрофанова, Е.А. (2012) Формирование готовности студентов колледжа к проектной деятельности: Автореф. дис. ... канд. пед. наук. СПб., 2012. 22 с.

Сараева, А.А. (2011) Формирование готовности будущих учителей к проектной 
деятельности в образовательном учреждении: Автореферат дис. ... канд. пед. наук. Самара, 24 с.

Стенина, Т.Л. (2011) Становление проектной культуры студентов. Ульяновск: УлГТУ, 243 с.

Усова, А.В. (1986) Формирование у школьников научных понятий в процессе обучения: монография. М.: Педагогика, 1986. 176 с.

Шамова, Т.И., Давыденко, Т.М. (1990) Управление процессом формирования систем качеств знаний учащихся: Метод. пособие. М.: Прометей. 112 с.

Юсупов В.3. (2019) Сущностные характеристики проектно-целевого подхода в развитии дополнительного образования //Научные труды Московского гуманитарного университета. 2019. № 4. [Электронный ресуpc] URL: http://journals.mosgu.ru/ trudy/article/view/1011 (Дата обращения: 23.07.2020.).

Юсупов Виталий Зуфарович - доктор педагогических наук, профессор кафедры педагогики и психологии высшей школы Московского гуманитарного университета. Адрес: 111395, Российская Федерация, г. Москва, ул. Юности, д. 5. Тел.: +7 (499) 374-74-59. Эл. адрес: pp.mosgu@mail.ru

Yusupov Vitaly Zufarovich - Doctor of Pedagogy, Professor, Department of Pedagogy and Psychology of Higher Education, Moscow University for the Humanities. Postal Address: 5, Yunosti St., Moscow, Russian Federation. Tel.: +7 (499) 374-74-59. E-mail: pp.mosgu@mail.ru

Капин Сергей Валериевич - директор Краевого государственного бюджетного профессионального образовательного учреждения «Норильский педагогический колледж». Адрес: 663300, Российская Федерация, Красноярский край, г. Норильск, ул. Комсомольская, д. 5. Тел.: +7 (3919) 46-03-02. Эл. адрес: Kapin73@mail.ru

Kapin Sergey Valerievich - Director of the regional state budgetary professional educational institution «Norilsk pedagogical College». Postal Address: 5 Komsomolskaya str., Norilsk, Krasnoyarsk territory, 663300, Russian Federation. Tel.: +7 (3919) 46-03-02. E-mail: Kapin73@mail.ru

\section{Для цитирования:}

Юсупов В.З., Капин С.В. Оценка когнитивной готовности выпускника педагогического колледжа к проектной деятельности // Научные труды Московского гуманитарного университета. 2020. №4. C. 4-11. DOI: https://www.doi.org/10.17805/trudy.2020.4.1 